\title{
O INCÊNDIO DO MUSEU NACIONAL NAS NARRATIVAS DAS “MULHERES DO RESGATE”: DESDOBRAMENTOS E PERSPECTIVAS.
}

The National Museum's Fire in the "Mulheres do Resgate's" narratives: developments and perspectives

\author{
Thaís Mayumi Pinheiro (D) \\ Mestre em Ciência da Informação - IBICT/UFRJ \\ Universidade Federal do Rio de Janeiro, \\ Rio de Janeiro, Brasil \\ thaismayumi@gmail.com \\ Cássia C.R.D. de Deus (iD \\ Mestre em Ciência da Informação - IBICT/UFRJ \\ Universidade Federal do Rio de Janeiro, \\ Rio de Janeiro, Brasil \\ cassiabiblio@ufri.br \\ Diana de Souza Pinto (D) \\ Doutora em Saúde Mental UFRJ \\ Universidade Federal do Estado do Rio de Janeiro, \\ Rio de Janeiro, Brasil. \\ dianap@globo.com
}

A lista completa com informações dos autores está no final do artigo

\section{RESUMO}

Este artigo aborda o incêndio do Museu Nacional/RJ como um desastre que representa um marco na história do país, devido à destruição de patrimônios científicos e culturais da humanidade. Suscita reflexões acerca da construção da memória do incêndio e pós-incêndio da instituição a partir dos vínculos conceituais entre memória, lugares de memória e patrimônio. Aponta o trabalho de resgate, que consiste na recuperação e tratamento dos fragmentos e peças dos acervos recuperados nos escombros do Paço de São Cristóvão, sede do Museu, como uma das primeiras atividades de retomada de suas atividades logo após o incêndio e, sobretudo, como um símbolo de resistência. Analisa as narrativas da campanha "Mulheres do Resgate", publicada nas redes sociais do Museu Nacional, com o propósito de observar como as pesquisadoras enunciam o incêndio e o resgate, observando quais são seus desdobramentos nos âmbitos pessoal, profissional e para o futuro do Museu Nacional. Apresenta os resultados da análise em cinco eixos temáticos (rotina institucional, incêndio, pós-incêndio, resgate e renascimento), ancorados na análise do discurso sociointeracionista e no campo da memória social. Com base no corpus de narrativas, aponta que a atuação do grupo "Mulheres do Resgate" opera na passagem discursiva do luto para a esperança. Finalmente, conclui que o Resgate é impulsionado pelo forte engajamento das envolvidas em reconstruir o Museu Nacional para a sociedade, destacando que as narrativas enunciadas integram a construção social de sua memória institucional.

PALAVRAS-CHAVE: Museu Nacional. Memória Social. Resgate de Acervos. Narrativa. Incêndio.

\begin{abstract}
The National Museum's/RJ fire was a disaster that represents a milestone in national history, due to the scientific and cultural human heritage's destruction. It raises reflections on the construction of the institution's fire and post-fire memory based on conceptual connections among memory, places of memory and heritage. This article highlights the rescue effort, which encompasses recovering and treating the fragments and pieces of the collections recovered in the rubble of the Paço de São Cristóvão, the Museum's headquarter, as one of the first resuming activities soon after the fire and, above all, a symbol of resistance. The narratives of the campaign "Mulheres do Resgate" (Rescue's Women) posted on the National Museum's social networks are analyzed in order to investigate how female researchers narrate the fire and the rescue, by observing their outcomes in their personal and professional lives as well as in the National Museum's future. The results of the analysis are presented in five thematic axes - institutional routine, fire, post-fire, rescue and rebirth grounded in both sociointeractional discourse analysis and social memory. The "Mulheres do Resgate's" performance works actively on the discursive transition from mourning to hope. Finally, the Rescue activity is driven by strong
\end{abstract}


engagement of those involved in rebuilding the National Museum for society, by highlighting that the narratives told by those women are an integral part of the social construction of the institutional memory.

KEYWORDS: National Museum. Social Memory. Redemption of Collections. Narratives. Fire.

\section{INTRODUÇÃO}

O incêndio do Museu Nacional da Universidade Federal do Rio de Janeiro (UFRJ), na noite do dia 2 de setembro de 2018, representa um marco na história do país. Não apenas os funcionários e o público do museu foram impactados por essa tragédia, como também grande parte dos brasileiros que assistiram à transmissão do incêndio na íntegra, divulgada publicamente em todas as estações de TV, rádio e mídias. Vimos e sofremos juntos a memória de um país queimar com a destruição do Museu. Pessoas de todo o mundo, por meio da imprensa e das mídias internacionais, tentavam contabilizar a destruição de patrimônios da humanidade, de anos de pesquisas de cientistas notáveis do país, da memória de povos que já não mais existem.

Das ruínas do Palácio Imperial, herança da Monarquia no Brasil, pouco foi recuperado do maior acervo de história natural e antropologia do país. Assistimos à perda de coleções únicas formadas ao longo dos 200 anos do Museu Nacional/UFRJ, frutos da dedicação de inúmeros pesquisadores, técnicos e cientistas. Foram queimados fósseis de muitos animais e plantas extintos, a maior coleção de artefatos egípcios da América Latina, exemplares da diversidade da fauna e flora do continente, a biblioteca de Antropologia Social, os registros linguísticos de povos indígenas que já não existem, entre muitos outros itens valiosos para a Cultura, a Memória e as Ciências nacionais. A perda é inestimável não apenas em função dos itens de sabida importância, mas também pelo potencial de descobertas científicas em milhões de itens que possivelmente ainda não haviam sido transformados em objetos integrais de pesquisas.

Embora, a princípio, não seja considerado como um grande desastre, que causa uma grande perda de vidas humanas, o incêndio e a perda do patrimônio do museu afetaram todos os aspectos da existência dessa comunidade e instituição, com a desorganização de suas redes materiais e simbólicas. Além disso, como em todo desastre, o Museu Nacional não pode se reconstruir sozinho, pois depende da ajuda de outros agentes estatais, parceiros institucionais e da mobilização da sociedade. Assim sendo, esse evento não se limita apenas ao dia de seu acontecimento, mas se desdobra ao longo de toda a etapa da sua longa recuperação. 
É importante destacar que o caso do Museu não é isolado. É parte de um processo histórico de falta de investimentos no próprio Museu Nacional mas também da série de incêndios de instituições culturais no Brasil que, somente nos últimos 10 anos, atingiram o Instituto Butantan (2010), o Memorial da América Latina (2013), o Museu de Ciências PUCMinas (2013), o Centro Cultural de Artes e Artesanato do Liceu (2014), o Museu da Língua Portuguesa (2015), a Cinemateca Brasileira (2016 e 2021) e, mesmo após o incêndio do Museu Nacional, a nova ocorrência no Museu de História Natural da UFMG (2020).

Apesar da difícil perspectiva de se pensar a reconstrução do Museu Nacional nesse cenário, muitas das suas atividades foram retomadas após o desastre, a exemplo de diversas iniciativas do Museu que objetivam continuar com as atividades junto ao público, desde eventos até exposições produzidas em outras instituições. Um exemplo foi a exposição promovida no Centro Cultural Banco do Brasil, a "Arqueologia do Resgate", que apresentou ao público, no período de 27/2/2019 a 29/4/2019, cerca de 180 itens, dos quais 103 são peças resgatadas das cinzas, inteiras ou danificadas (UFRJ, 2019). O trabalho de resgate teve início em 21 de setembro de 2018 e consiste na recuperação, triagem, identificação, tratamento dos fragmentos e peças dos acervos recuperados nos escombros do Palácio Imperial. A equipe do Resgate de Acervos, coordenada pela professora e arqueóloga Cláudia Carvalho, é formada por cerca de 45 técnicos e docentes, como também alunos e colaboradores, e encontrou, até o início de 2020, ao menos 5000 lotes e/ou peças (MUSEU NACIONAL, 2019, 2020).

No dia 08 de março de 2019, data de celebração do Dia Internacional da Mulher, o Museu Nacional lançou, em suas redes sociais (Facebook e Instagram), a campanha "Mulheres do Resgate", em homenagem ao Dia Internacional da Mulher. A campanha apresenta as pesquisadoras e técnicas envolvidas no resgate e, ao mesmo tempo, divulga a importância do trabalho para o público. Deve-se ressaltar que a campanha "Mulheres do Resgate" não se restringiu ao mês de março, porque continuou ativa, com novas publicações ao menos até julho de 2019. A proposta deste artigo é analisar as narrativas escritas da campanha produzidas pelas pesquisadoras e postadas nas referidas redes sociais observando como enunciam o incêndio e o resgate. Perguntamo-nos quais são os desdobramentos da perda desse patrimônio cultural e científico, para elas mesmas, para suas pesquisas, para o corpo técnico e para a sociedade. Também focalizaremos de que forma essas narradoras constroem discursivamente a atividade de resgate como um marco na memória do período pós-desastre e, consequentemente, para o futuro do Museu 
Nacional. O corpus da pesquisa que embasa este artigo compreende 14 narrativas, publicadas no período de 11 de março a 8 de julho de 2019.

O arcabouço teórico é multidisciplinar, pois é constituído na interface das áreas da Memória Social, ancorado em Halbwachs (1990), Pollack (2012), Gondar (2016), Nora (1993), Sarlo (2007), entre outros, da Museologia, por meio de Chagas (2011) e Loureiro et. al.(2007), e da Linguística Aplicada, mais especificamente na Análise de Narrativas (Linde, 2009; Mishler, 2002) e na Análise do Discurso de base sociointeracionista (Goffman, 1979), possibilitando-nos, assim, refletir acerca da construção da memória do incêndio do Museu Nacional como um processo narrativo coletivo e seletivo, que elege o que será lembrado e esquecido acerca dos acontecimentos/eventos. Entre eles, o trabalho de Resgate será abordado, sob a perspectiva de operação do patrimônio cultural, como uma iniciativa de recomeço de grande relevância.

\section{A MEMÓRIA DO INCÊNDIO E DO PÓS-INCÊNDIO DO MUSEU NACIONAL}

A memória pode ser analisada sob diferentes vieses; por estudos sobre sua constituição fisiológica, psicológica e social. Neste artigo, o foco será o aspecto social da memória, devido ao propósito de relacioná-la com os lugares de memória (Nora, 1993), com ênfase para os museus, a fim de evidenciar a importância da construção da memória incêndio e pós-incêndio do Museu Nacional enquanto patrimônios cultural e científico. Após a apresentação dos vínculos conceituais, intenciona-se demonstrar como uma parte do corpo técnico, especificamente, funcionárias do Museu que atuam no trabalho de Resgate, enunciam as perdas provocadas pelo incêndio e quais suas perspectivas para o futuro do Museu Nacional após o desastre.

A memória não deve ser compreendida apenas como fenômeno individual, conforme Halbwachs (1990) demonstrou em seus estudos; ela deve ser interpretada como um fenômeno social e coletivo. Na concepção do autor, a memória traduz como as operações mentais são estruturadas pelos arranjos sociais. "É na sociedade que as pessoas normalmente adquirem suas memórias. É também na sociedade que elas recordam, reconhecem e localizam as suas memórias." (HALBWACHS, 1990, p.38). Para Halbwachs (1990), a memória individual perpassa quadros sociais relacionados ao indivíduo. Os quadros sociais podem ser compreendidos como grupos de referência (por exemplo, 
família, escola, igreja, grupo de amigos ou no ambiente de trabalho) em que o indivíduo, em algum momento, vivenciou uma experiência ou com os quais estabeleceu pensamentos comuns que conformam as lembranças construídas e articuladas sob a percepção individual. Nesse sentido, verifica-se que a memória não pode ser dissociada do coletivo, porque, como o próprio autor afirma, nunca estamos sós; sempre estamos cercados pelos outros, mesmo que, em algumas situações, apenas estejam presentes os ensinamentos e as impressões. Assim, "todas as lembranças individuais ocorrem com materiais sociais, em contextos sociais e em resposta a estímulos sociais. Mesmo quando o fazemos sozinho, fazemos como seres sociais, com referência à identidade social" (OLICK, VINITTZKYSEROUSSI, LEVY, 2011, p. 79, tradução nossa).

A memória tanto individual quanto coletiva é considerada por Halbwachs (1990) e por Pollack (2012) como uma construção social ou um fenômeno construído e, por essa razão, está sujeita às circunstâncias do contexto em que é expressa. Observa-se, então, que a memória é atualizada e organizada em função das preocupações pessoais, sociais e políticas do momento. Esse entendimento suscita diversas questões no âmbito dos estudos da memória; entretanto, a mais pertinente ao escopo deste estudo é a característica seletiva da memória.

Ao determinar, a partir do contexto, como o passado será revisitado, escolhas são feitas, seja de forma consciente ou inconsciente, pois elas constituem a memória. Segundo Le Goff (1990), a memória molda a forma como nos lembramos do passado e, ao mesmo tempo, o que esquecemos. Dessa forma, "cada vez que escolhemos transformar determinadas ideias, percepções ou acontecimentos em lembranças, relegamos muitos outros ao esquecimento" (GONDAR, 2016, p. 29). A constatação de que a memória abrange o esquecimento possibilita um paralelo com o texto de Didi-Huberman (2017), para quem as lembranças sempre serão "cascas"1, fragmentos, pedaços retirados do passado no presente. $\mathrm{O}$ autor questiona-se sobre o que fará com as cascas ao longo do tempo; se as conservará, guardará ou esquecerá.

$\mathrm{Na}$ esfera do Museu Nacional, as escolhas sobre o que será lembrado e, consequentemente, esquecido sobre o incêndio e sobre as atividades pós-incêndio cabem principalmente aos funcionários, pesquisadores, diretores e diversos outros atores sociais dessa instituição. A seleção dessas memórias deve considerar que o "conceito de memória,

\footnotetext{
${ }^{1}$ No texto de Didi-Huberman (2017), as cascas foram retiradas pelo autor de uma das árvores do campo de concentração que visitou. $\mathrm{O}$ autor as classifica como um pedaço da memória.
} 
produzido no presente, é uma maneira de pensar o passado em função do futuro que se almeja." (GONDAR, 2005, p.17). A princípio, três considerações podem ser apresentadas com base nas questões abordadas. A primeira é que a construção da memória incêndio/pós-incêndio do Museu Nacional é coletiva. A segunda refere-se ao fato de que as escolhas devem suceder a reflexão sobre qual futuro se deseja para a instituição. Por último, a construção coletiva dessa memória repercutirá em como este passado será reconhecido pela instituição e por seus membros no porvir, projetando, assim, o que se deseja e o que se espera da sociedade, especialmente da comunidade que comporá o público que a visitará.

A construção coletiva de uma memória envolve a seleção de acontecimentos, aspectos e marcos (datas, monumentos, entre outros) julgados relevantes, que são reconhecidos como a "memória oficial" da sociedade para a posteridade. O uso das aspas tem a função aqui de demarcar o conflito não evidenciado, na maioria dos casos, na determinação desta memória. Para Pollack (1992), mesmo que não seja perceptível após a sua consolidação, a memória nacional é objeto de disputa e remete a um ponto de vista político. Nesse sentido, parte da memória coletiva é expressa nos lugares de memória, que "surgiram cooptados pela vontade de memória da nação e um investimento significativo dos poderes políticos na escrita da história" (SANTIAGO JÚNIOR, 2015, p. 253). Os lugares de memória são "museus, arquivos, cemitérios e coleções, festas, aniversários, tratados, processos verbais, monumentos, santuários, associações, são os marcos testemunhos de outra era [...] sinais de reconhecimento e de pertencimento de um grupo numa sociedade." (NORA, 1993, p. 13).

Ainda segundo Nora (1993), os lugares de memória englobam três sentidos simultâneos, passíveis de serem operados em graus diferentes, a saber: material, funcional e simbólico. O material está vinculado ao seu conteúdo demográfico, ou seja, a propriedade física. A funcionalidade é a hipótese do seu uso, que garante a cristalização da lembrança e sua transmissão. O último é o simbólico, "por definição, visto que caracteriza, por um acontecimento ou uma experiência vividos por um pequeno número, uma maioria que deles não participou" (NORA, 1993, p. 22). Enfim, conforme Nora (1993), a razão fundamental de ser um lugar de memória é bloquear o trabalho do esquecimento e materializar o imaterial. Assim, os lugares de memória configuram-se como uma das formas de materializar a memória que será relegada às próximas gerações.

Entre os lugares de memória, destacam-se os Museus, mas como aponta Chagas: 
$\mathrm{Na}$ atualidade, a afirmação de que os museus constituem lugares de memória passou a ser um lugar comum. Se nos anos 80 e 90 as investigações de Pierre Nora sobre os lugares de memória eram capazes de produzir impactos criativos, hoje seus impactos tendem a ser absorvidos, neutralizados e naturalizados (CHAGAS, 2011, p.11).

Faz-se necessário, então, desnaturalizar a relação entre memória e museu. Propomos aqui um retorno ao conceito conforme concebido por Nora (1993), entendendo a importância de que sejam feitas análises de museus considerando e destacando os sentidos que operam nesses lugares responsáveis pela construção de memórias.

O Museu Nacional, criado em 1818, é o museu e a instituição científica mais antiga do país. Estamos tratando, assim, do palco do nascimento da ciência brasileira, de onde partiram as nossas primeiras grandes expedições científicas, onde se desenhou a forma de fazer ciência no país, onde se estudaram nossos povos, nossa sociedade, nossa fauna, nossa terra e nossa flora. Além disso, o próprio prédio, o palácio de São Cristóvão, é um patrimônio em si que, antes de ser Museu, foi residência da família real/imperial portuguesa além de ter sediado a primeira assembleia constituinte da nossa República.

Loureiro et al. (2007) aponta que o Museu Nacional, como outros museus de história natural e antropologia em contexto de países de passado colonial, funcionou como aparato oficial de regulação político-ideológica da memória e do patrimônio nacional sob as lentes do conhecimento científico moderno. A partir disso é possível compreender a atuação do Museu Nacional como lugar que materializa desde a memória do Palácio Imperial (Monarquia no Brasil) até uma significativa parte da memória científica nacional, abarcando a memória tanto das coleções (procedência, constituição e trajetória), das pesquisas produzidas a partir delas, como também das produções de cientistas reconhecidos nacional e internacionalmente.

A partir do exposto, pode-se inferir que o Museu Nacional é reconhecido, simultaneamente, como um lugar de memória e patrimônio cultural e científico da sociedade. Enquanto lugar de memória, assume o valor material (todas as coleções, mobiliários e estrutura do palácio), funcional (exposições, inserção de jovens na ciência Programa de Iniciação Científica Júnior e outras iniciativas de ensino de pós-graduação, educação não-formal e pesquisas científicas) e simbólico (casa construída por traficante de escravos, residência da família real portuguesa e da família imperial brasileira, além de local da primeira Assembleia Constituinte Republicana, instituição científica mais antiga do Brasil e um dos maiores Museus de história natural e de antropologia das Américas). 
A ideia de patrimônio cultural "desempenha uma função social e simbólica de mediação entre o passado, presente e o futuro do grupo, assegurando sua continuidade no tempo e sua integridade no espaço" (GONÇALVES, 2007, p. 28). Essa mediação entre os tempos resguarda a preocupação de preservação e de transmissão da memória coletiva de um determinado grupo. Desse modo, o patrimônio é uma forma de atribuir valor, que visa a garantir a perpetuidade de rituais, marcos e símbolos da memória de uma cultura. Segundo Fabre (2013), patrimonializar é deslocar, colocar entre parêntesis, transformar algo em extraordinário, em outro patamar, atribuir outro valor, considerá-lo como um bem inalienável, sem valor de venda, mas significante para o coletivo.

Nessa linha de raciocínio, conforme Gonçalves (2007), o conjunto de objetos e bens materiais/imateriais designados como patrimônios culturais representa uma teia de pensamentos sobre a qual percebemo-nos individual e coletivamente. A partir dessa constatação, o referido autor atribui à categoria patrimônio cultural uma dimensão universal, que se manifesta de formas distintas em toda sociedade. Essa dimensão, segundo Fabre (2013), pode ser desdobrada em escalas de atuação: internacional, nacional e local. O Museu Nacional, de modo geral, é apreciado como patrimônio nas três esferas. Talvez a menos explorada em estudos até momento seja o valor local. No presente estudo, o foco será identificar como o corpo técnico, mais especificamente, como as pesquisadoras diretamente envolvidas no trabalho de Resgate enunciam as perdas do incêndio no Museu Nacional e quais os principais desdobramentos desse episódio para elas, para suas pesquisas, para a instituição e para a sociedade como um todo.

Como dito anteriormente, analisaremos segmentos das narrativas da campanha "Mulheres do Resgate". Cabe esclarecer, então, que a narrativa será tomada aqui conforme Linde (2009). Para a autora, ela é uma unidade discursiva que evoca os acontecimentos do passado e, ao mesmo tempo, sugere significados; logo, anuncia o valor desses eventos com suas respectivas implicações morais. Além disso, a consideramos como a verbalização da experiência, conforme Sarlo:

A narração da experiência está unida ao corpo e à voz, a uma presença real do sujeito na cena do passado. Não há testemunho sem experiência, mas tampouco há experiência sem narração: a linguagem liberta o aspecto mudo da experiência sem narração, redime-a de seu imediatismo ou de seu esquecimento e a transforma no comunicável, isto é, no comum. A narração inscreve a experiência em uma temporalidade que não é a de seu acontecer [...], mas a de sua lembrança (SARLO, 2007, p.24). 
Assim, a investigação da narrativa pessoal se configura como uma alternativa aos estudos que preconizam a linearidade temporal e, conforme Mishler (2002), propicia reinterpretar os significados de eventos passados com base nos efeitos provocados. Nesses casos, observa-se que "os enredos nessas narrativas pessoais são governados como um todo pelos seus modos de finalização, isto é, pela situação na qual os contadores se encontram depois de algo que Ihes aconteceu no passado." (MISHLER, 2002, p. 104). Desse modo, por meio da análise das narrativas, é possível identificar, pela ótica do narrador, os desdobramentos do evento, assim como a forma em que seu significado é elaborado e constituído em lembrança.

Outro aspecto das narrativas que será considerado é em que medida tanto a experiência da perda quanto da participação no resgate simbolizam um ponto de virada para as pesquisadoras/narradoras. De acordo com Mishler (2002), o ponto de virada é uma característica recorrente em narrativas de experiência pessoal, nas quais os efeitos dos incidentes, interpretados como algo repentino e inesperado, provocam mudanças na forma de agir, bem como na percepção sobre si próprio e/ou da sociedade. Por esse motivo, o autor explica que o ponto de virada envolve um processo de rehistorização, isto é, recontextualização do passado após o incidente, que pode levar à adoção de novas configurações identitárias, responsável por ressignificar as relações passadas.

No caso das narrativas do Resgate, pretende-se evidenciar a passagem do luto das pesquisadoras após o incêndio, do vazio da perda do patrimônio, para a reinvenção institucional, profissional e pessoal, além de destacar a relação das pesquisadoras com o Museu Nacional a partir da perspectiva do incêndio.

\section{METODOLOGIA}

Como já foi mencionado, o corpus da pesquisa é constituído por 14 segmentos de narrativas da campanha "Mulheres do Resgate", publicadas nas redes sociais (Facebook $e$ Instagram) do Museu Nacional, no período de 11 de março a 8 de julho de 2019. Frente à diversidade dos relatos, identificamos cinco eixos temáticos que permeiam e demarcam o enredo das experiências compartilhadas, com o propósito de sistematizar as análises, a saber: rotina institucional/profissional, incêndio, pós-incêndio, resgate e renascimento/futuro do Museu Nacional. Além de constituírem a estrutura organizacional, os eixos temáticos estão articulados também com o objetivo da pesquisa, uma vez que 
contemplam como as pesquisadoras, por meio da linguagem, se constroem antes e após o incêndio e como elaboram os seus efeitos, tanto na esfera pessoal quanto na institucional.

É importante esclarecer que dos 14 segmentos do corpus, apresentamos, nas análises, a íntegra ou trechos de 8 relatos. Em relação à seleção dos segmentos, no eixo rotina institucional, apenas alguns trechos são destacados a fim de demonstrar a diversidade das atividades exercidas de forma objetiva. A limitação de espaço condicionou a escolha de apenas um ou dois segmentos completos para os demais eixos. Portanto, o critério de seleção foi determinado pela relevância dos relatos, aspecto que embasou a eleição daqueles que ilustram pontos que atravessam todo o corpus da pesquisa.

\section{RESULTADOS}

Em cada um dos seguintes eixos, são analisados segmentos mais ilustrativos: rotina institucional/profissional, incêndio, pós-incêndio, resgate e renascimento/futuro do Museu Nacional.

\subsection{Rotina Institucional}

A seguir, destacam-se trechos das narrativas sobre as atuações profissionais de três pesquisadoras, a fim de demonstrar suas rotinas antes de se envolverem com o trabalho de resgate.

\footnotetext{
"Eu atuava no ensino e pesquisa, em especial na história do Palácio de São Cristóvão e da formação da ciência no Brasil." (Regina Dantas. Historiadora e docente).

"Muita coisa mudou porque antes a gente tinha uma rotina diária de trabalho, atuando na Reserva Técnica de Arqueologia." (Mariana Duarte. Arqueóloga e técnica do setor de Arqueologia).

"Estava acostumada com as minhas aulas e oficinas e, claro, de vez quando, trabalho de campo." (Luciana Carvalho. Paleontóloga e Vice Coordenadora do Resgate).
}

Na maioria dos relatos, devido ao vínculo do Museu Nacional com a Universidade Federal do Rio de Janeiro, observa-se a atuação em ensino por meio dos cursos de pósgraduação, além das atividades de pesquisa, curadoria de coleções e extensão. Destacase que apresentam uma descrição das atividades prévias ao incêndio e indicam como este impossibilitou a continuidade da rotina de trabalho por meio de expressões como "muita 
coisa mudou". No momento da campanha, ela foi alterada para a rotina do Resgate, de escavação do Palácio.

\title{
4.2 Incêndio
}

O incêndio do Museu, tópico importante e frequente nas narrativas, é associado de maneira recorrente a expressões que remetem à tristeza e ao pesar. As expressões "tragédia", "choque", "tudo estava perdido", "tudo tinha acabado", "perda total", entre outras de sentidos semelhantes, demarcam a reação das pesquisadoras quando se depararam com o incêndio. Por sua vez, o sentimento de dor causado pelo episódio é expresso por locuções tais como "completamente arrasada", "doloroso" e "de luto", que são comparáveis, nas palavras das narradoras, à perda de uma "pessoa querida". A intensidade do sentimento de perda é sublinhada, também, por meio do adjetivo "grande", do advérbio de intensidade "muito" e da justaposição de ambos na expressão "muito grande".

Dessa forma, o incêndio pode ser qualificado, em nosso corpus, como o "incidente" descrito por Mishler (2002), que ocasiona o ponto de virada, uma vez que a rotina de trabalho e a instituição são transformadas após sua ocorrência. Além do incêndio, o Resgate também é interpretado como um ponto de virada. Posteriormente, retomaremos esse ponto, mas vale salientar a analogia do Resgate ao renascimento e a uma nova identidade do Museu Nacional, conforme consta no relato a seguir:

\begin{abstract}
"Quando teve o incêndio, a sensação foi de perda total, como se tivéssemos perdido uma pessoa querida. No início, minha reação foi de negação, eu sentia um vazio muito grande por ter perdido tanto. Agora eu sinto que é um trabalho de desafio e por isso o resgate de acervos é tão importante. Cheguei a acreditar que não ia ter mais nada para restaurar, mas pelo contrário, vejo que a restauração vai ser essencial daqui para frente. Eu sinto um fôlego novo, sinto que estamos fazendo renascer o Museu Nacional. A nossa rotina de trabalho mudou completamente porque antes o laboratório que eu faço parte atendia o Museu de uma forma ampla, recebíamos todo o tipo de acervo. De repente, passamos a viver intensamente a rotina do resgate. Penso que o Museu daqui pra frente vai ser um outro museu, transformado. Ele vai sempre trazer essa recordação do passado, mas pode voltar a ser um grande museu. O que me impulsiona a continuar trabalhando é a vontade de salvar o máximo possível do acervo e abrir novamente o Museu ao público." (Mônica Coeli. Técnica em restauração do Laboratório Central de Conservação e Restauro).
\end{abstract}

\subsection{Pós - incêndio}


Os trechos selecionados demonstram o vazio gerado pelo incêndio. Tanto a personificação do Museu Nacional, ao associar a sua perda ao sentimento de luto, quanto a analogia do episódio à perda de uma casa, ambos demonstram o forte vínculo emocional das pesquisadoras, ou ainda, de forte pertencimento à instituição.

"Muita coisa mudou porque antes a gente tinha uma rotina diária de trabalho, atuando na Reserva Técnica de Arqueologia. Quando o incêndio aconteceu, a princípio eu pensei que tudo tinha acabado. Foi um período de luto mesmo. No meu caso, acho que teve um impacto ainda maior porque na época eu estava de licença maternidade. O que eu tinha na cabeça era aquele Museu que eu estava acostumada e quando eu voltei a trabalhar, já era outro Museu. E fui diretamente atuar no Resgate, na recuperação das peças da Reserva Técnica de Arqueologia. Hoje, eu acho que foi extremamente importante ter ido logo que voltei para o resgate, não apenas pelo Museu, mas também por mim. Depois do que aconteceu, foi importante para dar uma renovada e deixar de lado aquele sentimento de luto. Vou renovando cada vez mais quando vejo a quantidade de materiais essenciais que estamos encontrando. O resgate faz parte da minha rotina e da minha vida e hoje não me vejo trabalhando em outro lugar senão lá. Não estamos apenas recuperando a história do Museu Nacional, estamos ajudando o Museu a construir uma nova história." (Mariana Duarte. Arqueóloga, técnica, Setor de Arqueologia)

Outro ponto que merece destaque é o interesse em contribuir com a reestruturação do Museu Nacional. Verifica-se a mobilização das pesquisadoras, bem como o sentimento de resistência e esperança por meio de expressões como "salvar o Museu", "resistindo bravamente", "havia esperança lá dentro", “o Museu sobreviveu”, "o Museu continua vivo" e "Museu está vivo". Em suma, o choque do incêndio se desdobrou, ao mesmo tempo, em luto e ação.

\begin{abstract}
"A primeira impressão depois do incêndio foi um choque muito grande. Eu fiquei completamente arrasada e achando que tudo estava perdido. Mas imediatamente, no dia seguinte, nós descobrimos que o Museu sobreviveu. As paredes podem ter pegado fogo, mas o Museu continuava vivo. E quando vimos que mesmo após o incêndio as paredes resistiram, sabíamos que então havia alguma coisa lá dentro, resistindo bravamente contra essa ação destruidora. Não penso em me aposentar enquanto não terminar o resgate das coleções de Arqueologia, setor onde trabalho. A partir da montagem do grupo de resgate, a cada dia é uma boa surpresa. A esperança se renova a cada dia. É um grupo pequeno, muito otimista, que está trabalhando em uníssono. Temos um comprometimento e um companheirismo muito grande e estamos felizes, felizes por estar salvando e resgatando aquilo que a maioria acreditava não existir mais. O Museu Nacional vive e continua. Cada vez mais vivo." (Angela Rabello. Arqueóloga, Técnica de Coleções de Arqueologia)
\end{abstract}

\title{
4.4 Resgate
}


A campanha intitulada "Mulheres do Resgate" por óbvio, apresenta, em suas narrativas, um grande destaque para o trabalho de recuperação dos acervos do Museu nos escombros do Paço de São Cristóvão. Interessa-nos destacar aqui, portanto, como a experiência de cada uma dessas mulheres envolvidas neste trabalho é enunciada na forma de uma narrativa de experiência pessoal.

Observa-se, nas postagens, que após a introdução que tematiza a antiga rotina, o impacto do incêndio, o momento de choque e a consequente mobilização após a destruição, o trabalho de Resgate de Acervos é apresentado como a nova rotina, a atividade profissional com a qual todas estão profundamente comprometidas pessoal e profissionalmente.

Cabe destacar que o trabalho de Resgate é enunciado como uma ação coletiva e harmônica, para a qual todos os esforços convergem ("trabalho que passamos a realizar no resgate", "passamos a escavar a nossa própria casa"). São apontadas as razões para estar no Resgate, mas os interesses individuais indicados estão voltados para essa ação coletiva. Essa enunciação do Resgate é narrada como fruto de uma escolha, que nasce da dor da perda ("A gente fica triste, mas tenta deixar isso de lado"), alimentada também por uma memória de criação, conforme Gondar (2016), com vistas ao porvir da instituição ("A esperança se renova a cada dia", "Alimentamos nossa esperança a cada pedaço de objeto").

"Eu venho da Paleontologia, então trabalhar no resgate até tem um pouco do que eu já estava acostumada por conta dos trabalhos de campo. Mas aqui a gente realiza um trabalho que eu nunca pensei em fazer. $E$ mesmo estando acostumada com o pesado do trabalho de campo, o resgate tem um lado diferente porque ele mexe com o nosso emocional, com as nossas memórias do Museu, com a nossa história, com a nossa pesquisa. A gente fica triste, mas tenta deixar isso de lado. É um grande desafio e, felizmente, já tem mostrado bons resultados: conseguimos muitos itens do acervo, armários inteiros com dezenas de peças. Apesar da dor, apesar de tudo, o vínculo que temos com o Museu nos faz querer a todo custo estar aqui. Eu não me vejo em outro lugar, senão no resgate." (Uiara Gomes, Paleontóloga, Técnica de Coleções de Paleontologia)

"Eu atuava no ensino e pesquisa, em especial na história do Palácio de São Cristóvão e da formação da ciência no Brasil. Quando eu passei a ir todos os dias para o Palácio, atuando no resgate, foi muito impactante porque quase tudo que eu pesquisei foi sobre isso. Mas não teve outro jeito: eu arregacei as mangas, me envolvi completamente para conseguir reconstruir a história dessa casa. Estando ali no dia a dia do resgate é que estamos nos fortalecendo. Alimentamos nossa esperança a cada pedaço de objeto que conseguimos encontrar. Ninguém esperava que nós fôssemos conseguir encontrar tantas coisas, mas nós estamos conseguindo. Todo trabalho que está sendo feito agora também faz parte da história do museu. Nossa 
memória está salva. O Museu Nacional vive graças a esse envolvimento das pessoas acreditarem." (Regina Dantas, Historiadora)

Nas narrativas, a conjunção adversativa "mas" é usada de maneira muito frequente explicitando a virada, marcando discursivamente a passagem do momento de dor e tristeza para a superação.

A importância do Resgate está presente na maioria das narrativas que indicam a participação como inesperada "nunca pensei em fazer" e, ao mesmo tempo, como primordial "não há outra escolha possível" e "Eu não me vejo em outro lugar". Além disso, as expressões selecionadas pelas pesquisadoras são sempre de natureza positiva ("atividade extra que me fortalece", "idealistas", "equipe otimista", "esperança"). Observamos uma construção narrativa do Resgate associada à transformação da vida das envolvidas, que se alinham como agentes de uma nova missão profissional e institucional baseada na esperança e na união. A análise aponta também para o Resgate como um marco de resistência e reconstrução após o incêndio explicitado na recuperação de parte do acervo considerado perdido.

\subsection{Renascimento: presente e futuro do Museu Nacional}

Por fim, as narrativas da campanha enunciam como essas mulheres almejam o porvir do Museu Nacional por meio desse trabalho do presente. Um ponto recorrente é a importância dada à continuidade do trabalho na instituição e ao destaque ao que não foi perdido no incêndio (acervos e pessoas), contrariando as expectativas gerais face ao poder da destruição do fogo em um prédio tão antigo e com tantos objetos inflamáveis:

"Da noite para o dia passei a ir todos os dias para o palácio para atuar no resgate e minha vida virou de ponta a cabeça. Mas o engraçado é que essa rotina do resgate passou a ser mais familiar para mim do que as outras atividades. Isso porque não conseguia me imaginar fazendo outra coisa senão estar lá. Por já ter sido diretora do Museu por muito tempo, não sinto que ser coordenadora do resgate seja uma responsabilidade, mas sim um dever. O dever de trabalhar para reintegrar as peças, reintegrar o material $\mathrm{e}$ reintegrar a memória do Museu Nacional. As pessoas talvez não tenham noção da monumentalidade dessa instituição. Ainda temos coleções de extrema relevância científica que foram preservadas. $E$ o trabalho de resgate tem mostrado que ainda há muita coisa importante para ser recuperada, nós estamos reescrevendo e ressignificando nosso trabalho." (Cláudia Carvalho, Arqueóloga, Professora de Antropologia Biológica, Ex-diretora do Museu Nacional e Coordenadora do Resgate) 
Verifica-se, nos relatos, o uso frequente de verbos no presente, principalmente quando as pesquisadoras abordam a importância da instituição ("o museu vive", "o museu precisa", "temos coleções", "estamos reescrevendo"). Esse uso do tempo verbal sugere que o trabalho atual de resgate está ligado à ideia de vida, de (re)construção da memória, de experiência e de transformação. Sendo assim, parte do passado é recuperado por meio do resgate que, somado às partes preservadas, configuram-se como traços, "cascas", das coleções e do que é o Museu Nacional. E, assim, devem integrar as futuras coleções e recordações da instituição; portanto, conformam a memória construída no presente, com vistas ao porvir.

Outro aspecto identificado é a associação desse trabalho de resgate com o papel social do Museu e com o entendimento de que o futuro em construção tem, como um dos focos, o diálogo com seu público.

\begin{abstract}
"Bom, o incêndio foi um grande choque para todo mundo. Mas, em relação ao trabalho que passamos a realizar no resgate, embora muitas coisas tenham mudado em nossa rotina, de certa forma é muito similar ao trabalho que já realizávamos antes porque nós escavávamos sítios arqueológicos. A grande diferença é que passamos a escavar a nossa própria casa, o que acaba sendo muito doloroso. Mas ao mesmo tempo, é aquilo que podemos fazer. É bom saber que ainda temos o que fazer. A gente teve um tempo curtíssimo para processar o ocorrido porque sabíamos que precisávamos colocar a mão na massa o quanto antes para salvar o museu. Nós percebemos que nós estávamos vivos. E se nós estamos vivos, então, o museu está vivo, a sociedade está viva. Todas as pessoas que gostam do museu, que tinham afeto, todos que o visitavam, todos os colaboradores, todos aqueles que tinham alguma ligação com o museu passaram a se mobilizar. E se nós estamos mobilizados pelo Museu Nacional, então o Museu Nacional vive." (Silvia Reis. Arqueóloga e Técnica das coleções de Antropologia Biológica)
\end{abstract}

No último fragmento, constata-se a projeção discursiva do "eu" que compreende os papéis que a narradora assume durante o relato da experiência. $O$ estudo do sociólogo Erving Goffman relativo à interação (1979) introduziu o termo footing, traduzido por alinhamento, ao se referir aos múltiplos papéis que um narrador assume ao contar uma estória. O "footing representa o alinhamento, a postura, a posição, a projeção do "eu" de um participante na sua relação com o outro, consigo próprio e com o discurso em construção." (RIBEIRO, GARCEZ, 2013, p. 107). Essa categoria dos estudos da interação é central para distinguirmos quais são as identidades construídas nas narrativas. No relato acima, por exemplo, a narradora/pesquisadora posiciona-se como uma trabalhadora arqueóloga ("de certa forma é muito similar ao trabalho que já realizávamos antes porque nós escavávamos sítios arqueológicos"), determinada ("porque sabíamos que 
precisávamos colocar a mão na massa o quanto antes para salvar o museu") que se constrói no coletivo por meio da seleção do pronome "nós" e a expressão "a gente", reiteradas ao longo do segmento. A extensão da analogia de vidas daqueles que participam ativamente do resgate para a instituição e para a sociedade sublinham o afeto imbuído nas atividades de resgate que visam, sobretudo, à vida do Museu: "E se nós estamos vivos, então, o museu está vivo, a sociedade está viva."

\section{CONSIDERAÇÕES FINAIS}

A partir das análises das narrativas das trabalhadoras do Museu Nacional analisamos como a memória do incêndio é construída, conformando este evento como um desastre.

Primeiramente, observamos como o incêndio atingiu amplamente sua comunidade. Para além dos efeitos da perda dos aspectos tangíveis do patrimônio, da história e dos espaços de trabalho diário, essas mulheres enunciam a grande desorganização das suas redes simbólicas, indicadas pela descrição da rotina interrompida, pelos afetos e emoções provocados. Além disso, apontam as dificuldades do momento de reconstrução, desde os esforços intelectuais, emocionais até o esforço físico do trabalho de Resgate. Destacam o discurso da continuidade do Museu em meio à destruição e a necessidade da dedicação individual, mas, acima de tudo, da construção de um trabalho coletivo para recuperar a instituição. Referenciam, ainda, a importância da mobilização da sociedade, que é apontada como agente motivacional da reconstrução.

As narrativas também podem ser entendidas como expressão dos desdobramentos do incêndio, que não ficou circunscrito ao dia 02 de setembro de 2018, posto que teve seguimento no dia seguinte, nos momentos de luto e mobilização, no trabalho de Resgate dos acervos e nos trabalhos de reconstrução que continuam e continuarão mesmo alguns anos depois.

Se, para uma das pesquisadoras do Museu Nacional, elas não estão "apenas recuperando a história do Museu Nacional” mas sim "ajudando o Museu a construir uma nova história", podemos entender que suas estórias integram a construção social da memória do Museu Nacional. As narrativas, como vimos, evocam os acontecimentos do passado e criam significados e valores.

Considerando que a memória social deve ser analisada em seu contexto, este trabalho espera ter contribuído para a compreensão de que a memória do Museu Nacional 
está em produção por narradoras e narradores inseridos em um cenário catastrófico, de busca pela sobrevivência e continuidade de suas vidas profissionais, de toda uma comunidade institucional e, ainda, de um patrimônio cultural e científico da sociedade.

A análise das narrativas auxiliou-nos na identificação, pela ótica das Mulheres do Resgate, dos desdobramentos do desastre e das formas pelas quais o seu significado é elaborado e constituído em lembrança. Essas mulheres, alinhadas como parte fundamental da (e eventualmente como a própria) instituição, criam uma memória do desastre como momento de perda e superação. Em síntese, os relatos configuram-se como fragmentos de memória do trabalho de Resgate e, ainda, traduzem a relevância da linguagem como meio para elaboração da dor e da esperança.

Por fim, como vimos em Mishler (2002), as narrativas pessoais são também governadas pela situação na qual as contadoras das estórias se encontram depois de algo que lhes aconteceu. Assim, este trabalho evidenciou a luta coletiva de uma comunidade específica, em prol da manutenção e recriação do Museu Nacional, em um determinado período, demarcado por um contexto sociopolítico de sabido descaso com a Ciência, com o bem público e com a cidadania em nosso país. Portanto, está inserido no bojo das discussões e iniciativas que visam a salientar a relevância das instituições patrimoniais e científicas no Brasil. Consideramos que, em um contexto futuro, a depender dos rumos da instituição e do país, ela poderá ser enunciada e construída de outras formas.

\section{REFERÊNCIAS}

CHAGAS, Mário. Museus, memórias e movimentos sociais Museus, memórias e movimentos sociais. Cadernos De Sociomuseologia, n. 41. 2011. p. 5-16.

DIDI-HUBERMAN, Georges. Cascas. São Paulo: Editora 34, 2017.

DOUGLAS, Mary. Como as instituições pensam. São Paulo: EDUSP, 1998.

FABRE, Daniel. Le patrimoine porte par l'émotion. In: FABRE, Daniel. Émotions patrimoniales. Paris: MSH, 2013, p. 13-98.

GOFFMAN, Erving. Footing. In: Ribeiro, B.T.; Garcez, P. M. Sociolinguistica Interacional. 2. ed. São Paulo: Loyola, 2002, p. 107-148.

GOFFMAN, Erving. Sociolinguística interacional. 2. ed. São Paulo: Loyola, 2002.

GONÇALVES, José Reginaldo dos Santos. Antropologia dos objetos: Coleções, Museus e Patrimônios. Rio de Janeiro: Garamond, 2007. 
GONDAR. Jô. Cinco Proposições sobre Memória Social. Morpheus. n. 9, v. 15, p. 19-40, 2016.

GONDAR, Jô. Quatro Proposições sobre Memória Social, In: GONDAR, Jô; DODEBEI, Vera. O que é memória social, Rio de Janeiro: UNIRIO, 2005.

HALBWACHS, Maurice. A memória coletiva. São Paulo: Vértice, 1990.

LINDE, Charlotte. Working in the past: narrative and institutional memory. Oxford: Oxford Universtiy Press, 2009.

LOUREIRO, José Mauro Matheus; SOUZA, Daniel Maurício Viana de; SAMPAIO, Ana Cristina de Oliveira. Museus de História Natural e a Construção da "Nação". In: VIII ENANCIB - Encontro de Pesquisa em Ciência da Informação. Salvador, 2007.

MISLHER, Eliott. Narrativa e identidade: a mão dupla do tempo. In: LOPES, Luiz Paulo da Moita; BASTOS, Liliana Cabral. Identidades: recortes multi e interdisciplinares. Rio de Janeiro: Mercado das Letras, 2002.

MUSEU NACIONAL (Brasil). Resgate pós-incêndio. Rio de Janeiro: Museu Nacional. [2019]. Disponível em: http://www.museunacional.ufrj.br/destaques/resgate-posincendio.html. Acesso em: 19 jul. 2019.

MUSEU NACIONAL (Brasil). Museu Nacional: Panorama dos Acervos: Passado, Presente e Futuro. Rio de Janeiro: Museu Nacional, Universidade Federal do Rio de Janeiro, 2020. Disponível em:

http://www.museunacional.ufrj.br/destaques/docs/panorama_de_acervos/livro_acervos_m useu_nacional.pdf. Acesso em: 20 ago. 2020.

NORA, Pierre. Entre memória e história: a problemática dos lugares. Projeto História. São Paulo, n. 10, p.7-28, dez. 1993.

POLLAK, Michael. Memória e identidade social. Estudos Históricos. v. 5, n. 10, p. 200212, 1992.

OLICK, J. K.; VINITZKY-SEROUSSI, V.; LEVY, D. Introduction. In: OLICK, J. K.; VINITZKY-SEROUSSI, V.; LEVY, D. The collective memory reader. New York: Oxford University Press, p. 3-62, 2011.

RIBEIRO, Branca Telles; GARCEZ, Pedro M. Sociolinguística Interacional. São Paulo: Loyola, 2013.

SANTIAGO JÚNIOR, Francisco das Chagas F. Dos Lugares de Memória ao Patrimônio: emergência e transformação da 'Problemática dos Lugares'. Projeto História. São Paulo, n. 52, p. 245-279, jan.-abr. 2015.

SARLO, Beatriz. Tempo passado: cultura da memória e guinada subjetiva. Tradução Rosa Freire d'Aguiar. São Paulo: Companhia das Letras; Belo Horizonte: UFMG, 2007. p. 23-44. 
UNIVERSIDADE FEDERAL DO RIO DE JANEIRO. Museu Nacional vive: arqueologia do resgate. [Rio de Janeiro, RJ]: Universidade Federal do Rio de Janeiro. 28 fev. 2019. Disponível em: https://ufrj.br/noticia/2019/02/28/museu-nacional-vive-arqueologia-doresgate. Acesso em: 19 jul. 2019.

\section{NOTAS}

Thaís Mayumi Pinheiro

Mestre em Ciência da Informação - IBICT/UFRJ

Museóloga do Museu Nacional / Universidade Federal do Rio de Janeiro, Rio de Janeiro, Brasil

thaismayumi@gmail.com

Cássia C.R.D. de Deus

Mestre em Ciência da Informação - IBICT/UFRJ

Bibliotecária da Universidade Federal do Rio de Janeiro, Rio de Janeiro, Brasil

cassiabiblio@ufri.br

\section{Diana de Souza Pinto}

Doutora em Saúde Mental UFRJ

Professora Associada do Programa de Pós-Graduação em Memória Social da Universidade Universidade Federal do Estado do Rio de Janeiro, Rio de Janeiro, Brasil.

dianap@globo.com

Endereço de correspondência do principal autor

Thaís Mayumi Pinheiro

Rua Duvivier, 43/ apto 101 - Copacabana - CEP: 22020-020 - Rio de Janeiro/RJ, Brasil

\section{AGRADECIMENTOS}

Não se aplica.

\section{CONTRIBUIÇÃO DE AUTORIA}

Concepção e elaboração do manuscrito: DE DEUS, C.C.D., PINHEIRO, T.M., PINTO, D.D.S.

Coleta de dados: DE DEUS, C.C.D., PINHEIRO, T.M., PINTO, D.D.S.

Análise de dados: DE DEUS, C.C.D., PINHEIRO, T.M., PINTO, D.D.S.

Discussão dos resultados: DE DEUS, C.C.D., PINHEIRO, T.M., PINTO, D.D.S.

Revisão e aprovação: PINTO, D.D.S.

\section{CONJUNTO DE DADOS DE PESQUISA}

1) Todo o conjunto de dados que dá suporte aos resultados deste estudo foi publicado no próprio artigo.

\section{FINANCIAMENTO}

Não se aplica.

CONSENTIMENTO DE USO DE IMAGEM

Não se aplica

\section{APROVAÇÃO DE COMITÊ DE ÉTICA EM PESQUISA}

Não se aplica.

\section{CONFLITO DE INTERESSES}

Não se aplica.

\section{LICENÇA DE USO}

Os autores cedem à Revista Internacional Interdisciplinar INTERthesis os direitos exclusivos de primeira publicação, com o trabalho simultaneamente licenciado sob a Licença Creative Commons Attribution (CC BY) 
4.0 International. Estra licença permite que terceiros remixem, adaptem e criem a partir do trabalho publicado, atribuindo o devido crédito de autoria e publicação inicial neste periódico. Os autores têm autorização para assumir contratos adicionais separadamente, para distribuição não exclusiva da versão do trabalho publicada neste periódico (ex.: publicar em repositório institucional, em site pessoal, publicar uma tradução, ou como capítulo de livro), com reconhecimento de autoria e publicação inicial neste periódico.

\section{PUBLISHER}

Universidade Federal de Santa Catarina. Programa de Pós-graduação Interdisciplinar em Ciências Humanas. Publicação no Portal de Periódicos UFSC. As ideias expressadas neste artigo são de responsabilidade de seus autores, não representando, necessariamente, a opinião dos editores ou da universidade.

\section{EDITORES}

Javier Ignacio Vernal e Silmara Cimbalista

HISTÓRICO - uso exclusivo da revista

Recebido em: 24-09-2020 - Aprovado em: 04-10-2021 - Publicado em: 11-10-2021 